\title{
COMMUNICATION
}

\section{OPTICAL METAL-TO-LIGAND CHARGE-TRANSFER OF 2,2'-BIPYRIDYL COMPLEXES OF ANTIMONY(III) AND BISMUTH(III)}

\author{
HORST KUNKELY, ALOIS PAUKNER and ARND VOGLER $\dagger$ \\ Institut für Anorganische Chemie der Universität Regensburg Universitätsstraße 31, \\ D-8400 Regensburg, F.R.G.
}

(Received 20 July 1989; accepted 18 September 1989)

\begin{abstract}
The complexes [ $\mathrm{M}\left(2,2^{\prime}\right.$-bipyridyl) $\left.\mathrm{X}_{3}\right]$, with $\mathrm{M}=\mathrm{Sb}, \mathrm{Bi}$ and $\mathrm{X}=\mathrm{Cl}, \mathrm{Br}, \mathrm{I}$, are characterized by long-wavelength metal-to-ligand charge-transfer (MLCT) bands which determine the colours of these compounds in the solid state. The energy of the MLCT bands depends on the reducing strength of the metal and the extent of $s p$ mixing of the lone electron pair at the metal.
\end{abstract}

Coordination compounds of main group metals with a $s^{2}$ electron configuration at the metal show a large variety of different structures. Complexes of antimony(III) are good examples of this behaviour. ${ }^{1,2}$ This structural diversity depends-at least partially-on $s p$ orbital mixing. If this mixing occurs the lone electron pair gains $p$-character and becomes stereochemically active. In octahedral complexes such as $\left[\mathrm{TeBr}_{6}\right]^{2-}$ and $\left[\mathrm{SbCl}_{6}\right]^{3-}$, sp mixing does not take place and the lone pair preserves its $s$-character. The electronic spectra of $\left[\mathrm{TeBr}_{6}\right]^{2-3-5}$ and $\left[\mathrm{SBCl}_{6}\right]^{3-6-8}$ are relatively simple. They display long-wavelength absorptions in the UV. These bands belong to $s \rightarrow p$ transitions. On the contrary, there is not much known about the electronic spectra of complexes with a stereochemically active lone pair at the metal. In this case spectra assignments are certainly complicated due to the $s p$ orbital mixing and molecular structures of lower symmetry as imposed by the lone pair. However, an identification and characterization of the lone pair is feasible by electronic spectroscopy if a 1,2-diimine ligand such as 2,2'bipyridyl (bipy) or 1,10-phenanthroline (o-phen) is attached to the $s^{2}$ metal. Since these metals are reducing due to the presence of the lone pair, optical low-energy metal-to-ligand MLCT transitions should appear in analogy to diimine complexes of

$\dagger$ Author to whom correspondence should be addressed. reducing transition metals such as iron(II), ruthenium(II), or copper(I). ${ }^{9}$ With the exception of the organometallic cation $\left[\mathrm{Sn}^{\mathrm{II}}\left(\mathrm{C}_{5} \mathrm{Me}_{5}\right)\right.$ bipy] ${ }^{+10,11}$ such optical MLCT transitions of $s^{2}$ metal complexes are virtually unknown to our knowledge. In searching for simple examples our attention was drawn to the complexes $\left[\mathbf{M}(1,2\right.$-diimine $\left.) X_{3}\right]$, with $\mathbf{M}=\mathbf{S b}$, $\mathrm{Bi}, \mathrm{X}=\mathrm{Cl}, \mathrm{Br}, \mathrm{I}$, and 1,2-diimine $=$ bipy $^{12}$ and $o-$ phen. ${ }^{13,14}$ These compounds exhibit remarkable colours. We suspected that these colours are due to low-energy MLCT absorptions. In the present communication we report the first results on the electronic spectra and the spectral assignments of the complexes [M(bipy) $\mathbf{X}_{3}$ ].

Reliable absorption spectra of the complexes $\left[\mathrm{M}(\right.$ bipy $\left.) \mathrm{X}_{3}\right]$ in solution cannot be oblained since these compounds are either insoluble or undergo extensive dissociation in all common solvents, as indicated by the presence of free bipy which was identified by its absorption $\left(\lambda_{\max }=280 \mathrm{~nm}\right.$, $\varepsilon=11230$ and $\lambda_{\max }=235 \mathrm{~nm}, \varepsilon=9160$ ) and fluorescence $\left(\lambda_{\max }=325 \mathrm{~nm}\right)$ spectra. The spectra of the complexes were measured by scattered transmission spectroscopy of suspensions of the powdered materials in hexane or paraffin and recorded in absorbance vs wavelength on a Uvikon 860 spectrometer equipped with an end-on photomultiplier. The spectra are characterized by long-wavelength bands in the visible region which determine the colour of the complexes (Fig. 1, Table 1). In 
Table 1. Colours and optical MLCT transitions of $\left[\mathrm{M}(\right.$ bipy $\left.) \mathrm{X}_{3}\right]$ in the solid state

\begin{tabular}{lcccccc}
\hline $\mathrm{MX}_{3}$ & $\mathrm{SbCl}_{3}$ & $\mathrm{SbBr}_{3}$ & $\mathrm{SbI}_{3}$ & $\mathrm{BiCl}_{3}$ & $\mathrm{BiBr}_{3}$ & $\mathrm{BiI}_{3}$ \\
\hline $\begin{array}{l}\text { Colour } \\
\lambda_{\max }(\mathrm{nm})\end{array}$ & $\begin{array}{c}\text { Bright yellow } \\
360\end{array}$ & $\begin{array}{c}\text { Orange } \\
435\end{array}$ & $\begin{array}{c}\text { Dark red } \\
545\end{array}$ & $\begin{array}{c}\text { White } \\
326\end{array}$ & $\begin{array}{c}\text { Cream } \\
390\end{array}$ & $\begin{array}{c}\text { Orange-red } \\
485\end{array}$ \\
\hline
\end{tabular}

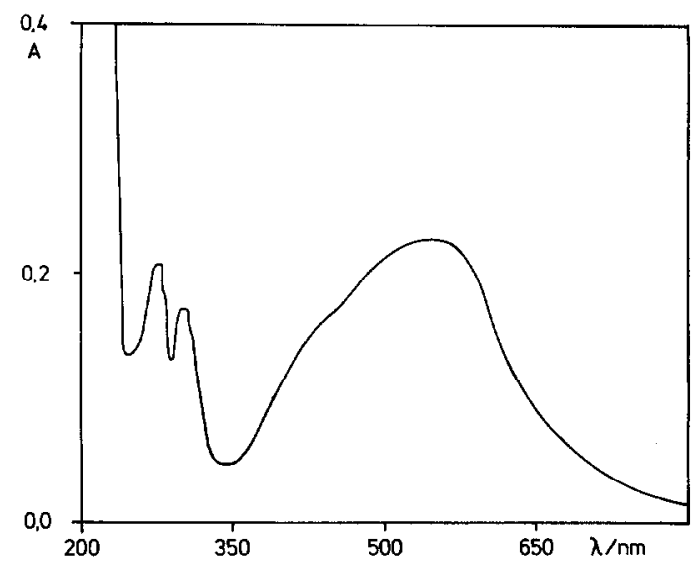

Fig. 1. Electronic absorption spectrum of $\left[\mathrm{Sb}\right.$ (bipy) $\left.\mathrm{I}_{3}\right]$ at room temperature; absorbance in arbitrary units.

addition, absorptions also appear at shorter wavelength in the UV (Fig. 1).

The absorption spectra of the $\left[\mathbf{M}(\right.$ bipy $\left.) \mathbf{X}_{3}\right]$ complexes all contain a maximum slightly above 300 $\mathrm{nm}$ which is assigned to the lowest-energy $\pi \rightarrow \pi^{*}$ intraligand transition of the bipy ligand. These bands also appear in the spectra of bipy complexes of transition metals such as rhodium ${ }^{15,16}$ or platinum $^{17}$ and are indicative of coordinated bipy. Ligand-to-metal charge-transfer transitions involving the promotion of a halide electron to the $p$ orbitals of $\mathrm{M}^{\mathrm{III}}$ are not expected to occur at low energies. For example, $\left[\mathrm{SbCl}_{6}\right]^{3-}$ does not show LMCT absorptions at wavelengths above $200 \mathrm{~nm}^{6-}$ ${ }^{8}$ The long-wavelength absorptions of $\left[\mathrm{M}(\mathrm{bipy}) \mathrm{X}_{3}\right]$ (Fig. 1, Table 1) are then logically assigned to MLCT transitions involving the promotion of an electron from the lone pair of the metal to the $\pi^{*}$ orbital of the bipy ligand. This assignment is supported by the blue shift of this band which takes place when antimony(III) is replaced by bismuth(III) (Table 1). Bismuth(III) is generally less reducing $\left(\mathrm{Bi}^{\mathrm{III} / \mathrm{V}}: E^{0} \sim 1.7 \mathrm{~V}\right)$ than antimony(III) $\left(\mathrm{Sb}^{\mathrm{III} / \mathrm{V}}\right.$ : $\left.E^{0} \sim 0.6 \mathrm{~V}\right){ }^{18}$ The MLCT assignment of the lowenergy absorptions of $\left[\mathrm{M}(\right.$ bipy $\left.) \mathrm{X}_{3}\right]$ is thus quite obvious. However, the blue shift of the MLCT bands in the series $\mathrm{X}=\mathrm{I}, \mathrm{Br}$, and $\mathrm{Cl}$ requires some further explanations.

It has been concluded from the Mössbauer spectra that the $p$ character of the lone pair of
[M(diimine) $\left.\mathrm{X}_{3}\right]$ increases from $\mathrm{X}=\mathrm{I}$ to $\mathrm{Br}$ and $\mathrm{Cl} .^{13}$ The $s p$ orbital mixing which is achieved by a configuration interaction leads then to a stabilization of the lone pair. ${ }^{19}$ Accordingly, the MLCT transition of $\left[\mathrm{M}\right.$ (bipy) $\left.\mathrm{I}_{3}\right]$ occurs at rather low energies since the lone pair has less $p$ contribution. On the contrary, the larger $p$ character of the lone pair of $\left[\mathrm{M}(\right.$ bipy $\left.) \mathrm{Cl}_{3}\right]$ shifts the MLCT transition to higher energies.

The origin of this difference in $s p$ mixing does not seem to be clear. It may be related to the spatial demand of the ligand $X$. The configuration interaction which leads to the $s p$ mixing requires a distortion from a more symmetrical structure. ${ }^{19}$ Simultaneously, space opens for the lone pair which becomes stereochemically active. This steric flexibility is provided by the smaller $\mathrm{Cl}^{-}$ligand rather than by the $\mathrm{I}^{-}$ligand. Unfortunately, the structures of these complexes are not to our knowledge known. On the basis of IR measurements it has been suggested that the complexes [M(diimine) $\mathrm{X}_{3}$ ] consist of bridged dimers or chain polymers. ${ }^{13,14,20}$

\section{REFERENCES}

1. J. F. Sawyer and R. J. Gillespie, Prog. Inorg. Chem. $1986,34,65$.

2. U. Ensinger, W. Schwarz and A. Schmidt, $Z$. Naturfor. 1983, 38b, 149 and literature cited therein.

3. D. A. Couch, C. J. Wilkins, G. R. Rossman and H. B. Gray, J. Am. Chem. Soc. 1970, 92, 307.

4. D. J. Stufkens, Recl. I'rav. Chim. 1970, 89, 1185.

5. A. Vogler and A. Paukner, J. Photochem. Photobiol. 1989, 46A, 227.

6. R. A. Walton, R. W. Matthews and C. K. Jørgensen, Inorg. Chim. Acta 1967, 1, 355.

7. L. Kolditz, W. Schiller and J. Kunze, Z. Anorg. Allg. Chem. 1973, 395, 207.

8. A. Vogler and A. Paukner, Inorg. Chim. Acta 1989, $163,207$.

9. A. B. P. Lever, Inorganic Electronic Spectroscopy. Elsevier, Amsterdam (1984).

10. F. X. Kohl, E. Schlüter, P. Jutzi, C. Krüger, G. Wolmershäuser, P. Hoffmann and P. Stauffert, Chem. Ber. 1984, 117, 1178.

11. P. Jutzi, Adv. Organomet. Chem. 1986, 26, 217.

12. W. R. Roper and C. J. Wilkins, Inorg. Chem. 1964, 3, 500 .

13. N. Bertazzi, G. Alonzo and T. C. Gibb, Inorg. Chim. Acta 1983, 73, 121. 
14. G. Alonzo, M. Consiglio, N. Bertazzi and C. Preti, Inorg. Chim. Acta 1985, 105, 51.

15. D. H. W. Carstens and G. A. Crosby, I. Molec. Spectrosc. 1970, 34, 113.

16. M. Nishizawa, T. M. Suzuki, S. Sprouse, R. J. Watts and P. C. Ford, Inorg. Chem. 1984, 23, 1837.

17. A. Vogler and H. Kunkely, Angew. Chem. Int. Edn Engl. 1982, 21, 209.
18. G. Milazzo and S. Caroli, Tables of Standard Electrode Potentials. John Wiley, New York (1978).

19. T. A. Albright, J. K. Burdett and M.-H. Whangbo, Orbital Interactions in Chemistry, p. 263. John Wiley, New York (1985).

20. A. M. Brodie and C. J. Wilkins, Inorg. Chim. Acta $1974,8,13$. 